\title{
Antler Mass of Barren-Ground Caribou Relative to Body Condition and Pregnancy Rate
}

\author{
DON THOMAS ${ }^{1}$ and SAM BARRY $Y^{1,2}$
}

(Received 8 July 2003; accepted in revised form 20 December 2004)

\begin{abstract}
Antlers of caribou (Rangifer tarandus) likely contribute to breeding success of males, defence of feeding sites by females, and recognition of the hierarchical status of conspecifics. However, few data are available on how antler mass is related to age, body mass, fat reserves, other physical indices, and reproduction. Mass of antlers was recorded for 958 caribou obtained in early and late winter, 1982 through 1987, from the Beverly herd of barren-ground caribou (R. t. groenlandicus) in north-central Canada. In females, antler mass increased with age to 14 years, whereas mean body mass was stable from 7 through 13 years. Female antler mass correlated with body mass, body size, fat indices, and pregnancy rate both among and within age classes. In males, antler mass correlated highly with lean body mass to age 4 years. Antler mass varied among years in concert with fatness in females and with changes in body mass in both sexes. We conclude that antler mass is an index of body mass, body size, condition, and pregnancy rate, but high variation makes it inferior to other indices.
\end{abstract}

Key words: antler and body mass, Arctic, Subarctic, fat indices, pregnancy rate, Rangifer tarandus

RÉSUMÉ. La ramure du caribou (Rangifer tarandus) contribue probablement au succès de la reproduction chez le mâle, à la défense des aires d'alimentation chez la femelle et à la reconnaissance du statut hiérarchique parmi les congénères. On possède toutefois peu de données sur la façon dont le poids de la ramure est relié à l'âge, à la masse corporelle, aux réserves de gras, à d'autres indices physiques et à la reproduction. On a consigné le poids des ramures pour 958 caribous prélevés au sein de la harde Beverly de caribous des toundras (R. t. groenlandicus) dans le centre-nord du Canada, au début et à la fin de l'hiver, de 1982 à 1987. Chez la femelle, le poids de la ramure augmentait avec l'âge jusqu'à 14 ans, alors que de 7 à 13 ans, la moyenne de la masse corporelle était stable. Chez la femelle, le poids de la ramure était en corrélation avec la masse corporelle, la taille du corps, les indices de gras et le taux de gestation entre les groupes d'âge et au sein de ces groupes. Chez le mâle, le poids de la ramure était fortement corrélé avec la masse corporelle maigre jusqu'à l'âge de 4 ans. Le poids de la ramure variait d'une année à une autre de concert avec l'adiposité chez la femelle, et de concert avec les changements dans la masse corporelle chez les deux sexes. On conclut que le poids de la ramure constitue un indice de la masse corporelle, de la taille du corps, de l'état corporel et du taux de gestation, mais que sa grande variation en fait un indice inférieur à d'autres.

Mots clés: ramure et masse corporelle, Arctique et Subarctique, indices de gras, taux de gestation, Rangifer tarandus

Traduit pour la revue Arctic par Nésida Loyer.

\section{INTRODUCTION}

Rangifer tarandus (caribou and reindeer) have the most morphologically elaborate and variable antlers of all members of the deer family, and this species is unique in that females, as well as males, have antlers. They function in males as offensive weapons in contests for dominance and display to attract females (Bubenik, 1975). Antlers are organs of combat with defensive characteristics and features that reflect age, body size, and physical condition. Most evidence of their function in females points to a role in defence of feeding craters in snow (Barrette and Vandal, 1986; Schaefer and Mahoney, 2001). They also may serve as a means of instant recognition of conspecific individuals ranked in a social hierarchy.

Our objective is to examine antler mass in caribou relative to age, body size indices, fat indices, pregnancy, and year in samples obtained during six winters. Antler mass may provide a useful index of body condition and past environmental conditions. We compare results with those of Prichard et al. (1999), who correlated mass of growing (velvet) antlers of free-ranging reindeer with age, body mass, lactational state, and year. We emphasize degree of association, as measured by coefficients of determination $\left(R^{2}\right)$, and degree of difference, as indicated by confidence intervals.

\footnotetext{
${ }^{1}$ Canadian Wildlife Service, Room 200, 4999-98 Avenue, Edmonton, Alberta T6B 2X3, Canada

${ }^{2}$ Corresponding author: Sam.Barry@ec.gc.ca

(C) The Arctic Institute of North America
} 


\section{METHODS}

\section{The Sample}

Between March 1982 and March 1987, 1171 caribou were sampled from the Beverly herd (Thomas and Kiliaan, 1998a). That population of 200000 to 400000 adult caribou generally migrates between its winter range in the forests of northern Manitoba, Saskatchewan, and the Northwest Territories and its summer range on the tundra in Nunavut and the Northwest Territories. With assistance from members of the Fort Smith Hunters and Trappers Association, we positioned tent camps near the front of large aggregations. We shot caribou non-selectively (except for avoiding calves) over several days as groups passed by. Therefore, samples were about as random as possible from a population of migratory caribou. Collection periods were 25 November-15 December (five "December samples") and 13-29 March (six samples).

Antlers were numbered and labelled left or right, sawed off at the pedicle, and returned to the laboratory for weighing on electronic balances. Whole body mass, including antlers, was measured to the nearest $0.5 \mathrm{~kg}$ on a dial scale supported by a pole tripod. Initially, girth was measured immediately behind the front leg with a steel tape tensioned to about $2 \mathrm{~kg}$; however, that measurement was discontinued after March 1984 because of time constraints. Back fat was measured at maximum depth along a cut anterio-lateral to the base of the tail (Dauphiné, 1976). Both kidneys and surrounding fat were removed and placed in labelled plastic bags. Trimmed fat (Dauphiné, 1976) from each kidney was weighed and summed. The mandible was removed and labelled in the field, and its length was obtained by vernier caliper according to Banfield (1961). The femur was removed in the field and subsequently measured with a vernier caliper parallel to its long axis. Reproductive state was recorded on field data sheets, and fetuses were retained.

Age to previous birthday was estimated from stained sections of both the first incisor and the first molar. Ages were pooled if Bonferroni differences in antler mass between year classes were not significant at $95 \%$ probability and there was no within-age-group variation in analysis of variance. In females, there were five such groups: calf; yearling; $2-4$ years $\left(F=2.10_{[2,257]}, p=0.13\right) ; 5-10$ years $\left(F=1.30_{[5,291]}, p=0.26\right)$; and over 10 years $\left(F=0.37_{[4,48]}\right.$, $p=0.83)$. We term the last three age groups as "young," "mature," and "old" females, respectively. Means for antler mass were symmetrical in age classes of females (Thomas and Kiliaan, 1998a), which enabled us to double the mass of single antlers and add them to pairs to create a synthetic group termed 'two antlers.' However, in males over two years, antler pairs were heavier than singles doubled, and pairs were lighter in March than in December (Thomas and Kiliaan, 1998a). Therefore, some analyses were restricted to mass of antler pairs in December samples. Males five and six years old also were excluded because each age contained only one individual, and both likely had light antlers and late shedding. "Year" is growth year as expressed by antler mass in samples obtained the following December and March.

\section{Statistical Analyses}

The need for normalization of variables varied with sex and age groupings. Square root best transformed mass of antlers and kidney fat for females, but natural log was best for males. Three outliers were excluded, including an antler mass of $836 \mathrm{~g}$ in a 12-year-old female.

Relationships between antler mass and physical variables were estimated using correlation, analysis of covariance (ANCOVA), general linear models (GLM), linear regression, and logistic regression. Selected variables were limited to age, body mass, girth, mandible length, femur length, thickness of back fat, mass of kidney fat, pregnancy, and year. Preliminary data analysis indicates that our selected indices of skeletal size and fatness were the least variable of several indices (Thomas and Kiliaan, 1998a). We built multiple regressions by manual entry of variables as they ranked in correlation with antler mass. Minimum retention of a variable was at $p<0.05$. Interaction of variables was included in models, but none was significant. Body mass correlated highly with all size and condition variables in all females $(r=0.59-0.82)$ and in mature females $(r=0.45-0.60)$. We included only one skeletal measurement and one fat index in models because they were highly correlated. Growth ceased statistically (ANOVA $p<0.05$ ) in females at two years (femur length), four years (body mass), and seven years (mandible length).

We checked distribution of residuals graphically while performing regressions and GLM. We report $R^{2}$ rather than adjusted $R^{2}$ because our results are descriptive rather than predictive. All references to "differences" in antler mass and other variables indicate statistically significant differences $(\alpha=0.05)$.

\section{RESULTS}

Antler Mass Relative to Age, Body Mass and Size, and Fat Indices

In females, antler mass (AM) increased with age to 14 years (Fig. 1). A regression for pregnant females was: square root $A M=13.573+0.445 \mathrm{Age}\left(R^{2}=0.150, F=99.2\right.$, $n=519)$. There was no overlap of $95 \%$ confidence intervals of AM among the five age groups (Table 1). In males, $\log \mathrm{AM}$ in December increased quadratically with age to four years: $\log (A M)=3.677+1.694 \bullet$ Age $-0.195 \bullet$ Age $^{2}$; $\left(R^{2}=0.995, F_{[3,89]}=5837, p<0.001\right)$.

Body mass (BM) correlated highest with AM in both sexes (Table 2). Age, BM, girth, and skeletal size each explained much AM variance in growing males, whereas coefficients of determination $\left(R^{2}\right)$ were much lower in 


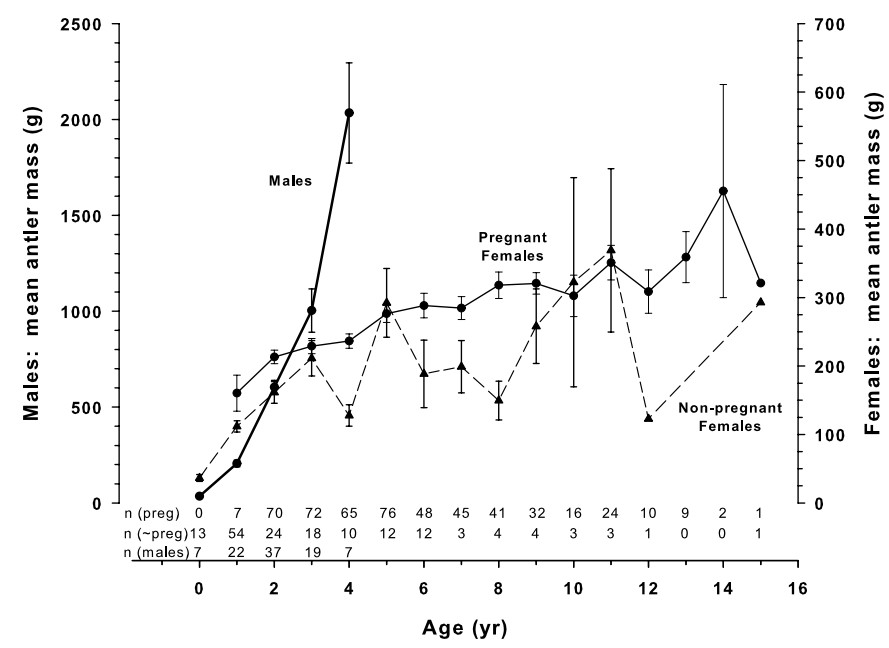

FIG. 1. Age-specific mean antler mass and standard error of male (December samples) and female caribou (December and March samples), Beverly herd, 1982 through 1987.

growing females and in all females. Fat indices had low $R^{2}$ values in both sexes.

For females, none of the selected variables in combination explained more than $46 \%$ of the variance in AM in December or $51 \%$ in March. BM and age, as a categorical variable, together explained $43.1 \%$ of the variance in females in December and 50.8\% in March. In pooled data from December and March $(n=682), \mathrm{BM}$ and age together explained $47.6 \%$ of the variance in AM. (Individually, BM accounted for $42.6 \%$ and age for $25.1 \%$.) The best fit $\left(R^{2}=49.5 \%\right)$ was BM with age as covariate $(n=683)$. A good fit $\left(R^{2}=48.8 \%\right)$ was BM, age, and girth $(\mathrm{n}=301)$; however, BM and girth were highly correlated $(r=0.82)$. In males sampled in December, adding age to BM increased $R^{2}$ from $85.2 \%$ to $89.9 \%$, the best fit.

In December, AM comprised $0.34 \%$ of BM of females more than four years old and $1.85 \%$ of BM of males aged four years. The ratio of AM to BM (\%) in males in December increased progressively with age from one to four years, as follows: $0.30,0.69,1.00$, and 1.85 . This ratio was $2.57 \%$ in the only male caribou six years old still bearing antlers in late November.

\section{Antler Mass Relative to Condition Indices within Age Classes}

In both sexes, AM correlated highest with BM within age groups (Table 3). Including other variables with BM had only small effects. For example, in mature females, adding girth and femur length to BM increased $R^{2}$ from $17.9 \%$ to $20.2 \%$. In young females, addition of girth to BM increased $R^{2}$ from $24.4 \%$ to $30.0 \%$. In best-fit models, $R^{2}$ was $49 \%$ for pooled ages, $30 \%$ in young females, and $21 \%$ in mature females. Annual variation accounted for $2.3 \%$ of the variance in AM in young females and $0.1 \%$ in mature females.

\section{Annual Changes in Antler Mass}

With age as a covariate, AM varied $(p<0.001)$ among years in females older than calves $\left(F=11.90_{[5,664]}\right)$, in young $\left(F=5.11_{[5,252]}\right)$ and mature females $\left(F=9.22_{[5,290]}\right)$, and in males $\left(F=4.86_{[5,225]}\right)$. Adding BM as a second covariate removed some of the annual variation in AM. However, year as a covariate remained significant in all females $(F=3.67, p=0.003)$, females older than calves $(F=5.62, p<0.001)$, and males aged one to four years $(F=4.57, p<0.001)$. With $\mathrm{BM}$ as the single covariate, annual variation remained significant within age groups of females (e.g., age $>0: n=670, F=3.40, p=0.001$; age 5-10: $n=276, F=4.40, p<0.001)$ and males (e.g., age $1-4: F=3.69, p=0.003)$.

In mature females, averge AM declined 34\% from 1981 to 1982 , increased $48 \%$ to 1984 , and then declined $31 \%$ to 1986. There were parallel changes in BM (Fig. 2a) and fat indices (Fig. 2b). The same trends in AM occurred in young and old females and in males, except that AM increased from 1985 to 1986 in young females and males (no data for old females in 1986). In yearling males, after an initial decline of $38 \%$, AM increased markedly from $143 \mathrm{~g}(95 \% \mathrm{CI}=113-174 \mathrm{~g}, n=22)$ in 1982 to $282 \mathrm{~g}$ $(95 \% \mathrm{CI}=205-380 \mathrm{~g}, n=13)$ in 1986.

\section{Antler Mass Relative to Pregnancy}

Pregnancy explained $19.2 \%$ of the variance in AM in all females and $25.4 \%$ in females under five years of age. However, reproductive state was not significant when BM

TABLE 1. Antler mass ( $\mathrm{g}$ ) of female and male caribou sampled from the Beverly herd, 1982-87.

\begin{tabular}{|c|c|c|c|c|c|c|c|}
\hline \multicolumn{4}{|c|}{ 'Two antlers,' females ${ }^{1}$} & \multicolumn{4}{|c|}{ Antler pairs, males } \\
\hline $\mathrm{Age}^{2}$ & Mean & $95 \% \mathrm{CI}^{3}$ & $n$ & Age & Mean & $95 \% \mathrm{CI}^{3}$ & $n$ \\
\hline 0 & 37 & $26-48$ & 13 & 0 & 38 & $31-45$ & 16 \\
\hline 1 & 117 & $101-133$ & 61 & 1 & 230 & $199-260$ & 65 \\
\hline $2-4$ & 215 & $204-226$ & 260 & 2 & 580 & $530-630$ & 105 \\
\hline $5-10$ & 286 & $272-300$ & 297 & 3 & 1003 & $765-1242^{4}$ & 19 \\
\hline$>10$ & 345 & $310-379$ & 52 & 4 & 2034 & $1394-2674^{4}$ & 7 \\
\hline
\end{tabular}

${ }^{1}$ Antler pairs plus double mass of single antlers.

${ }^{2}$ Age in years, where calves $=0$ and yearlings $=1$ year.

${ }^{3}$ Non-overlap of confidence interval (CI) indicates a strong difference.

${ }^{4}$ December samples. In March samples, antler mass was significantly lower in age class 4 years. 
TABLE 2. Coefficients of determination $\left(R^{2}\right)$ between antler mass (AM) and variables for pooled ages in samples obtained in December and March, 1982-87, from the Beverly herd of caribou.

\begin{tabular}{|c|c|c|c|c|}
\hline \multirow[b]{2}{*}{ Variable } & \multicolumn{4}{|c|}{$R^{2}$ of $\mathrm{AM}^{1}$ and selected variables by sex, age, and month } \\
\hline & $\begin{array}{c}\text { Males < 5, Dec } \\
n=108^{2}\end{array}$ & $\begin{array}{c}\text { Females }<5, \text { Dec } \\
n=110^{2}\end{array}$ & $\begin{array}{l}\text { All females, Dec } \\
n=205^{2}\end{array}$ & $\begin{array}{c}\text { All females, March } \\
n=478^{2}\end{array}$ \\
\hline Body mass (kg) & 0.852 & 0.427 & 0.355 & $0.457^{3}$ \\
\hline Age (years) & 0.772 & 0.198 & 0.197 & 0.277 \\
\hline Girth $(\mathrm{cm})$ & 0.797 & 0.342 & 0.211 & $0.391^{3}$ \\
\hline Mandible length (mm) & 0.712 & 0.305 & 0.250 & 0.226 \\
\hline Femur length (mm) & 0.731 & 0.171 & 0.094 & $0.191^{3}$ \\
\hline Back fat $(\mathrm{mm})$ & $0.034^{4}$ & 0.140 & 0.135 & 0.191 \\
\hline Kidney fat $(\mathrm{g})^{3}$ & 0.148 & 0.183 & 0.134 & 0.143 \\
\hline Pregnancy rate & & 0.206 & 0.208 & $0.200^{3}$ \\
\hline
\end{tabular}

${ }^{1}$ Antler mass and kidney fat transformed by square root (females) and natural log (males).

${ }^{2}$ Maximum sample size. For some variables, maximum is slightly smaller. For girth, it is much smaller: $n=49,35,73$, and 228 (left to right).

${ }^{3}$ One outlier removed (Case 47, AM 836 g).

${ }^{4}$ The only statistically insignificant value $(p=0.055)$.
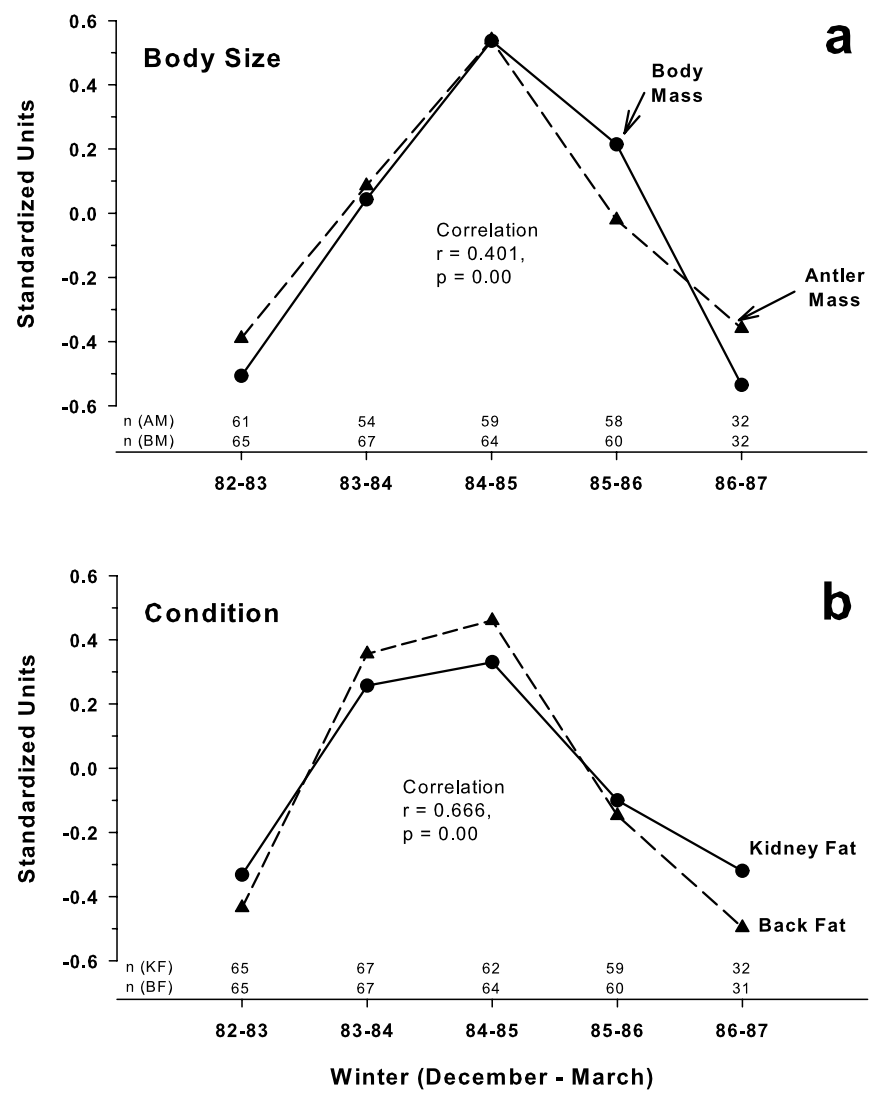

FIG. 2. Annual changes in standardized measurements of female caribou 5-10 years old in winters 1981-82 through 1986-87 in the Beverly herd of caribou: (a) antler and body mass; (b) back fat depth and kidney fat mass.

or age was added to the model. Antlers tended to be lighter in non-pregnant females than in pregnant ones (Fig. 1), and these differences were significant in young females (95\% CI $147-197 \mathrm{~g}$ vs. $214-238 \mathrm{~g}, n=52,207)$ and mature females (183-289 g vs. 280-308 g, $n=38,258)$. We related those differences in AM to differences in BM of non-pregnant and pregnant young females $(95 \% \mathrm{CI}$ $69.7-73.3 \mathrm{~kg}$ vs. $82.1-82.9 \mathrm{~kg}, n=58,231)$ and mature females (74.0-79.4 kg vs. $85.3-87.1 \mathrm{~kg}, n=42,277)$.

A logistic regression model for females older than calves yielded probabilities of pregnancy with AM as the independent variable (Fig. 3). In spite of the good fit, high variation in $\mathrm{AM}$ makes it inferior to $\mathrm{BM}$ as a predictor of pregnancy. The coefficient of variation $(\mathrm{CV})$ of $\mathrm{AM}$ in females older than four years was 4.8 times that of BM and 15.9 that of femur length $(\mathrm{CV}=0.430,0.089$, and 0.027). Corresponding multiples in males two to four years old were 4.8 for $\mathrm{BM}$ and 18.9 for femur length $(\mathrm{CV}=0.624$, 0.131 , and 0.033 ).

\section{DISCUSSION}

Our results are remarkably similar to those obtained for reindeer with mass of growing antlers in velvet adjusted according to date of antler removal (Prichard et al., 1999). Similarities were as follows: (1) an increase in AM with age in females, (2) a flattening of the AM growth curve in the female age classes from two to four years, (3) similar $R^{2}$ values in both subspecies for BM and age and much higher values in males than in females, (4) more variance in AM explained by BM than by age, and (5) annual variation in AM not entirely explained by changes in BM. Replication of these previous results adds credibility to our observational studies.

Body condition in female caribou in the adjacent Kaminuriak (now Qamanirjuaq) herd did not change from September to November/December (Dauphiné, 1976), and therefore our results for winter samples should represent body condition at the rut. Kidney fat mass increased significantly between December and March, perhaps as a consequence of significant declines in kidney mass (Thomas and Kiliaan, 1998a).

It is logical that BM would fit best with AM among and within age classes of caribou because it was highly 
TABLE 3. Single variables yielding the best fit when regressed with mass (Y in grams) of two antlers within age classes of female caribou (pooled December and March samples) and with mass of antler pairs in males (December samples), Beverly herd.

\begin{tabular}{|c|c|c|c|c|c|}
\hline Sex/age & $n$ & Equation $^{1}$ & Slope $S E$ & $R^{2}$ & $t$ \\
\hline F 1 & $\begin{array}{l}47 \\
61\end{array}$ & $\begin{array}{l}Y=-22.18+0.133 \text { mandible length }(\mathrm{mm})^{2} \\
Y=0.900+0.153 \text { body mass }(\mathrm{kg})\end{array}$ & $\begin{array}{l}0.038 \\
0.043\end{array}$ & $\begin{array}{l}0.211 \\
0.174\end{array}$ & $\begin{array}{l}3.46^{3} \\
3.53\end{array}$ \\
\hline $\mathrm{F} 2-4$ & $\begin{array}{r}260 \\
92 \\
238\end{array}$ & $\begin{array}{l}\mathrm{Y}=-0.929+0.190 \text { body mass }(\mathrm{kg}) \\
\mathrm{Y}=-17.87+0.281 \text { girth }(\mathrm{cm}) \\
\mathrm{Y}=-22.87+0.143 \text { mandible length }(\mathrm{mm})\end{array}$ & $\begin{array}{l}0.021 \\
0.054 \\
0.024\end{array}$ & $\begin{array}{l}0.244 \\
0.229 \\
0.127\end{array}$ & $\begin{array}{l}9.12 \\
5.18 \\
5.86\end{array}$ \\
\hline $\mathrm{F}>10$ & 52 & $\mathrm{Y}=16.33+0.145$ back fat $(\mathrm{mm})$ & 0.045 & 0.171 & 3.21 \\
\hline M 1 & 22 & $\mathrm{Y}=3.292+0.028$ body mass $(\mathrm{kg})$ & 0.013 & 0.198 & 2.22 \\
\hline M 2 & $\begin{array}{l}35 \\
35\end{array}$ & $\begin{array}{l}\mathrm{Y}=3.338+0.035 \text { body mass }(\mathrm{kg})^{2} \\
\mathrm{Y}=-1.082+0.027 \text { mandible length }(\mathrm{mm})\end{array}$ & $\begin{array}{l}0.005 \\
0.007\end{array}$ & $\begin{array}{l}0.562 \\
0.288\end{array}$ & $\begin{array}{l}6.50 \\
3.65\end{array}$ \\
\hline
\end{tabular}

${ }^{1}$ Antler mass (Y) transformed by square root (females) and natural log (males).

${ }^{2}$ One outlier excluded (Studentized residual $>3.0$ ).

${ }^{3}$ All $t$ values are significant with two-tailed Student test $(p<0.05)$.

correlated with all selected variables. In lean males, the fit with BM increased sharply from age one to two years and was maintained at age three. Obviously there is stronger selection for large body and antler size in males than in females. The driver, of course, is breeding success. Genetic potential obviously is dampened by the energetic requirements of reproduction, particularly in young females, and environmental conditions, including resource restrictions, costs of migration, and insect harassment. The strongest evidence of a nutritional effect was annual variation in $\mathrm{AM}$ in both sexes that paralleled condition trends. However, annual variation in AM persisted even when BM, the strongest correlate among and within age classes, was controlled as a covariate. Therefore, although restricted nutrition limits antler and condition indices in a similar pattern (Fig. 2), there are other factors influencing AM.

Our results from winter samples must be interpreted with respect to annual cycles in antlers (Bergerud, 1976), body growth, and body condition (Dauphiné, 1976) relative to reproduction in both sexes. Our samples were composed mostly of lean, young males because mature males typically shed their antlers before December and then separate from large aggregations of females. Consequently, strong correlation between AM and BM is expected in winter. Residual variance of $10 \%$ in pooled males one to four years old is likely to be of genetic and environmental origin. We expect that fatness would correlate with AM in adult males before the rut. Low correlation with fat in females is explained in part by the fact that antler growth largely ceases before fat is deposited in late summer and autumn (Dauphiné, 1976).

There was high residual variance of about $50 \%$ in AM of females in spite of fat indices accounting for low yet

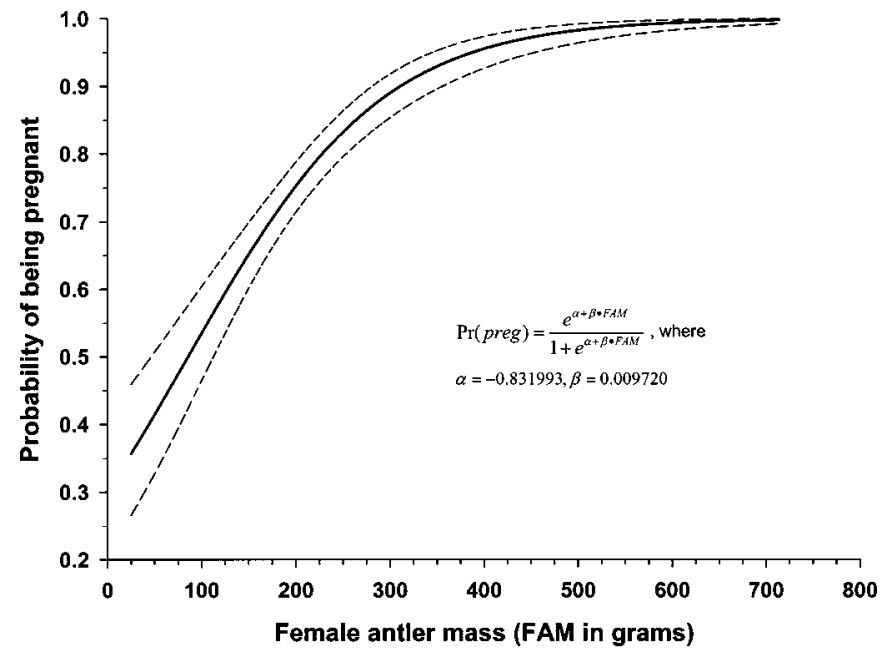

FIG. 3. Logistic regression and $95 \%$ confidence intervals estimating probability of pregnancy from antler mass of female caribou older than calves in the Beverly herd of caribou, 1981-82 through 1986-87.

significant variance (Table 3). Greater AM in pregnant females than non-pregnant ones is consistent with differences in BM and fat indices. Some unexplained variance may be attributed to differences in reproductive history involving differential timing of antler growth and costs associated with calf nurturing. Costs would vary greatly depending on length of calf survival.

Non-pregnant females have new-growth, velvet antlers up to $5 \mathrm{~cm}$ long when most parturient females are shedding 11-month-old antlers in mid to late June. Antler growth in parturient females begins in late June and early July, when body condition is poorest (Dauphiné, 1976) and competition for calcium, energy, and other resources is high. 
Lactating caribou are expected to have lighter antlers than dry females, as reported for reindeer (Prichard et al., 1999).

Any benefit of heavy (large) antlers in females appears to be weak. There may be a trade-off between long-term benefits of large antlers and their cost, particularly in growing females. Costs include not only production of bone in antlers, which amounts to $0.35 \%$ of $\mathrm{BW}$ in females older than four years, but also blood loss from insects when antlers are in velvet.

Antler mass can be used to estimate pregnancy rate (Fig. 3) if large, random samples are obtained, though BM and fat indices are much better predictors (Thomas and Kiliaan, 1998b). However, the results of this study have other potential applications. Where the kill exceeds sustainable harvest, selection by hunters of females with large, complex antlers would increase the relative kill of old females and thereby reduce the overharvest problem for two reasons. First, old females have lower reproductive potential and a higher mortality rate than young females (Thomas and Barry, 1990a, b). Second, from 1980 through $1987,61 \%$ of calves produced by females one to three years old in the Beverly herd were female calves, whereas only $33 \%$ of calves produced by old females were females (Thomas et al., 1990). Those young and old age classes represented about $33.4 \%$ and $9.4 \%$ of females older than calves, and they produced $38.2 \%$ and $7.3 \%$ of sampled female calves (Thomas and Barry, 1990b). The effect of such a selective harvest over time would be a reduction in population decline. Conversely, shooting too high a proportion of old females may affect leadership and migration patterns, and it may increase the take of productive mature females with large antlers.

Our study was designed to assess the adequacy of winter range for the Beverly herd; therefore, observations of relationships between AM and possible explanatory variables are limited by timing of samples, restricted ages of males bearing antlers, and lack of reproductive history for females. The strengths of the study lie in its long duration, large sample size, and data on age and body condition of each individual studied. Ideally, samples should be obtained just before the rut from caribou of known reproductive history. However, the option to sacrifice radio-collared animals is seldom available, and removal of antlers for weighing could influence future AM and body composition. In spite of their limitations, our data help to explain antler mass variation in caribou.

\section{ACKNOWLEDGEMENTS}

The many people who helped obtain samples of caribou are listed in Thomas and Kiliaan (1998a). Jim Schaefer and other members of the Fort Smith Hunters and Trappers Association organized field camps in early years and supported the studies. Earl Evans conducted field camps and shot most of the caribou, efficiently and humanely. Henk Kiliaan participated in the field collections and conducted many of the laboratory tasks. Frank Miller, Marco Festa-Bianchet, and two anonymous reviewers improved drafts of the paper. We thank the Department of Indian and Northern Affairs and Environment Canada for funding this study.

\section{REFERENCES}

BANFIELD, A.W.F. 1961. A revision of the reindeer and caribou genus Rangifer. National Museum of Canada, Bulletin 177, Biological Series 66. 137 p.

BARRETTE, C., and VANDAL, D. 1986. Social rank, dominance, antler size, and access to food in snow-bound wild woodland caribou. Behaviour 97:118-146.

BERGERUD, A.T. 1976. The annual antler cycle in Newfoundland caribou. Canadian Field-Naturalist 90:449-463.

BUBENIK, A.B. 1975. Significance of antlers in the social life of barren-ground caribou. Biological Papers, University of Alaska Special Publication 1:436-461.

DAUPHINÉ, T.C., Jr. 1976. Biology of the Kaminuriak population of barren-ground caribou. Part 4: Growth, reproduction and energy reserves. Canadian Wildlife Service Report Series 38. Ottawa: Minister of Supply and Services. 69 p.

PRICHARD, A.K., FINSTAD, G.L., and SHAIN, D.H. 1999. Factors affecting velvet antler mass in free-ranging reindeer in Alaska. Rangifer 19:71-76.

SCHAEFER, J.A., and MAHONEY, S.P. 2001. Antlers of female caribou: Biogeography of the bones of contention. Ecology 82(12):3556-3560.

THOMAS, D.C., and BARRY, S.J. 1990a. Age-specific fecundity of the Beverly herd of barren-ground caribou. Rangifer, Special Issue 3:257-263.

- 1990b. A life table for female barren-ground caribou in north-central Canada. Rangifer, Special Issue 3:177-184.

THOMAS, D.C., and KILIAAN, H.P.L. 1998a. Fire-caribou relationships: (I) Physical characteristics of the Beverly herd, 1980-87. Canadian Wildlife Service Technical Report Series 309. Edmonton, Alberta. 178 p.

1998b. Fire-caribou relationships: (II) Fecundity and physical condition of the Beverly herd. Canadian Wildlife Service Technical Report Series 310. Edmonton, Alberta. 96 p.

THOMAS, D.C., BARRY, S.J., and KILIAAN, H.P.L. 1990. Fetal sex ratios in caribou: Maternal age and condition effects. Journal of Wildlife Management 53:885-890. 